\title{
Penggunaan Limbah Beton Sebagai Agregat Pada Campuran Stone Matrix Asphalt Halus
}

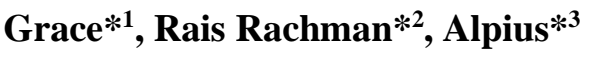 \\ *1 Mahasiswa Program Studi Teknik Sipil, Universitas Kristen Indonesia Paulus Makassar, \\ Indonesiagrace7mn@gmail.com \\ *2,3 Dosen Program Studi Teknik Sipil, Universitas Kristen Indonesia Paulus Makassar, Indonesia \\ ${ }^{2}$ rais.rachman@gmail.com ${ }^{* 2}$ dan alpiusnini@gmail.com ${ }^{* 3}$
}

Corresponding Author: alpiusnini@gmail.com

\begin{abstract}
Abstrak
Limbah beton di Indonesia pada umumnya belum dipergunakan dengan baik dan dibiarkan tanpa ada penanganan yang akan menimbulkan permasalahan tersendiri bagi lingkungan, maka dari itu perluh pengolahan supaya bisa digunakan menjadi bahan yang lebih berguna. Penelitian ini bertujuan untuk mengetahui karakteristik limbah beton untuk digunakan dalam campuran Stone Matrix Asphalt, mengetahui komposisi campuran Stone Matrix Asphalt menggunakan limbah beton dan mengetahui kemampuan campuran terhadap pengaruh suhu dan air setelah perendaman. Metodologi penelitian menggunakan metode Marshall Konvensional untuk mendapatkan karakteristik limbah beton yang digunakan dalam campuran Stone Matrix Asphalt dan Marshall Immersion untuk mendapatkan nilai stabilitas Marshall Sisa. Hasil penelitian menunjukkan bahwa karakteristik agregat limbah beton memenuhi persyaratan untuk campuran perkerasan jalan. Berdasarkan rancangan komposisi campuran didapatkan komposisi campuran untuk kadar aspal $6,00 \%$ agregat kasar yaitu $69,00 \%$, agregat halus $15,67 \%$, dan filler 8,33 . Penggunaan campuran Stone Matrix Asphalt Halus melalui pengujian Karakteristik campuran Marshall Konvensional diperoleh nilai Stabilitas, Kelelehan (flow), Void In Mix (VIM), Void In Mix Aggeregate (VMA), memenuhi spesifikasi, hasil pengujian Marshall Immersion diperoleh indeks perendaman sebesar atau Kekuatan Sisa 92,02\% artinya campuran tahan terhadap lamanya perendaman.
\end{abstract}

Kata kunci: Limbah beton, SMA halus, Marshall test

\begin{abstract}
Concrete waste in Indonesia in general has not been used properly and is left without any handling which will cause its own problems for the environment, therefore it needs processing so that it can be used as a more useful material. This study aims to determine the characteristics of the concrete waste to be used in the Stone Matrix Asphalt mixture, determine the composition of the Stone Matrix Asphalt mixture using concrete waste and determine the ability of the mixture to influence temperature and water after immersion. The research methodology uses the Conventional Marshall method to obtain the characteristics of the waste concrete used in the mixture of Stone Matrix Asphalt and Marshall Immersion to obtain the Marshall Residual stability value. The results showed that the aggregate characteristics of the waste concrete met the requirements for the mixture of road pavements. Based on the mixed composition design, the composition of the mixture obtained for asphalt content is 6.00\%, coarse aggregate is $69.50 \%$, fine aggregate is $16.00 \%$, and filler is 8.50 . The use of a mixture of Stone Matrix Asphalt Smooth through testing Characteristics of the Conventional Marshall mixture obtained Stability,
\end{abstract}


Meltability (flow), Void In Mix (VIM), Void In Mix Aggregate (VMA) values, meet the specifications, Marshall Immersion test results obtained an immersion index of or Residual Strength $92.02 \%$ means that the mixture is resistant to the duration of immersion.

Keywords: Concrete waste, SMA fine, Marshall test.

\section{PENDAHULUAN}

Kekurangan sumber daya alam dalam menyediakan material pembentuk beton merupakan sebuah masalah yang penting di mana pembangunan infrastruktur di Indonesia sekarang ini sudah mengalami peningkatan sangat pesat, peningkatan ini dibutuhkan agar keperluan akan bahan yang dibutuhkan dengan mudah dan cepat tersedia [1]. Beton merupakan suatu bahan yang kerap berkembang sampai sekarang ini. Biasanya material yang dibutuhkan dalam pembuatan beton secara murni di setiap daerah mengakibatkan kerusakan alam [2].

Limbah beton merupakan suatu material yang di mana sudah tidak dipergunakan lagi dan dibuang di sembarang tempat yang akan menyebabkan lingkungan menjadi tercemar. Pembuangan limbah padat seperti ini pada dasarnya dapat mengurangi kerusakan lingkungan jika dilakukan daur ulang atau mengolah limbah tersebut sebagai pengganti agregat. Memanfaatkan material limbah beton sehingga dapat digunakan kembali dengan nilai ekonomis struktur yang lebih tinggi [3] [4]. Dengan begitu daur ulang merupakan salah satu cara yang digunakan untuk meminimalkan atau mengurangi jumlah sampah yang ada sehingga dapat meningkatkan nilai ekonomis serta meningkatkan nilai gunanya [5] [6].

Dalam penggunaannya ada kelebihan serta kekurangan dari limbah beton yaitu limbah beton mempunyai tingkat kekuatan dan kuat tekan yang tinggi dari ciri-ciri limbah beton tersebut mampu memberikan keuntungan apabila diperlukan sebagai agregat dalam menggantikan agregat alami pada campuran beraspal. Disisi lain limbah beton mempunyai kekurangan di mana limbah beton mempunyai kuat tarik yang minim sehingga limbah beton cepat retak dalam penggunaannya [7].

Beberapa penelitian yang meneliti tentang penggunaan material dengan menggunakan limbah beton yang sudah terpublikasi dalam jurnal antara lain Imannurrohman dkk (2020) tentang pemanfaatan limbah beton sebagai pengganti agregat kasar pada perkerasan laston asphalt concrete-wearing coarse (AC-WC) [8]. Maulana dkk (2020) meneliti tentang pemanfaatan limbah beton sisa pengujian sebagai substitusi agregat pada campuran AC-WC [9]. Siang dan Makmur (2020) meneliti tentang pengaruh penggunaan limbah beton terhadap parameter marshall campuran beraspal berpori [10]. Saepudin (2016) meneliti tentang kajian penggunaan limbah beton sebagai pengganti agregat kasar pada campuran cement treated base $(C t b)$ untuk lapis pondasi perkerasan [11]. Wilujeng dan Risdianto (2019) meneliti tentang pemanfaatan limbah beton sebagai bahan campuran aspal porus [12].

Selain penelitian tersebut beberapa penelitian mengenai campuran SMA yang pernah dilakukan sebagai bahan perkerasan jalan antara lain Abdillah dkk (2018) meneliti tentang pengaruh penggunaan bahan tambah viatop ${ }^{66}$ pada campuran Stone Matrix Asphalt terhadap titik lembek aspal dan sifat drain down campuran [13]. Suaryana (2012) meneliti tentang kajian material Stone Matrix Asphalt Asbuton berdasarkan kriteria deformasi permanen (a study of stone matrix asphalt asbuton material based on permanent deformation criterion) [14]. Kurniawan dan Lubis (2019) meneliti tentang alternatif penggunaan serat eceng gondok pada campuran stone matrix asphalt gradasi halus meningkatkan stabilitas campuran aspal panas [15]. 
Tujuan dari penelitian ini yaitu untuk mengetahui karakteristik dari limbah beton untuk digunakan dalam campuran Stone Matrix Asphalt, mengetahui komposisi campuran Stone Matrix Asphalt yang menggunakan limbah beton dan mengetahui kemampuan campuran terhadap pengaruh suhu dan air setelah perendaman.

\section{METODOLOGI}

\section{Pengambilan Material}

Material dari limbah beton yang akan dipergunakan diambil dari laboratorium struktur dan bahan Universitas Kristen Indonesia Paulus Makassar, lokasi pengambilan material itu sendiri dekat dari tempat penelitian yang akan dilaksanakan, material yang telah dipersiapkan kemudian di bawah ke laboratorium untuk diuji.

\section{Perancangan Komposisi Campuran}

Pada rancangan komposisi campuran untuk penelitian ini bahan yang akan digunakan yaitu agregat kasar dan halus (limbah beton), Aspal penetrasi 60/70 yang diperoleh dari balai pengujian dan penelitian aspal Departemen Umum (DPU) Baddoka Makassar, Bahan pengisi (semen). Komposisi campuran yang akan digunakan yaitu:

Tabel 1. Komposisi Campuran Stone Matrix Asphalt Halus

\begin{tabular}{cccccc}
\hline \multirow{2}{*}{ Material } & \multicolumn{5}{c}{ Kadar Aspal (\%) } \\
\cline { 2 - 6 } & $\mathbf{6 , 0 0 \%}$ & $\mathbf{6 , 2 5 \%}$ & $\mathbf{6 , 5 0 \%}$ & $\mathbf{6 , 7 5 \%}$ & $\mathbf{7 , 0 0 \%}$ \\
\hline Agregat kasar (gr) & 634 & 832.5 & 831 & 829.5 & 828 \\
\hline Agregat Halus(gr) & 192 & 191 & 190 & 198 & 188 \\
\hline Filler (gr) & 102 & 101.5 & 101 & 100.5 & 100 \\
\hline Aspal (gr) & 72 & 75 & 78 & 81 & 84 \\
\hline
\end{tabular}

\section{Persiapan Sampel Benda Uji}

Benda uji yang akan digunakan pada penelitian ini yaitu sebanyak 18 buah, dimana untuk pengujin Marshall Konvensional yaitu 15 buah untuk setiap variasi kadar aspal yang digunakan sebanyak 3 sampel dan untuk pengujian Marshall Immersion sebanyak 3 buah.

\section{Pengujian Marshall Konvensional}

Tujuan dari pengujian ini yaitu untuk mendapatkan kekuatan dari campuran beraspal pada stabilitas, flow, analisa kepadatan, dan pori dalam campuran yang akan diteliti [16] [17] [18]. Parameter dari pengujian ini yaitu stabilitas, flow, VIM, VMA yang di mana parameter ini telah didapatkan maka lanjut ke grafik hubungan kadar aspal dengan setiap parameter yang digunakan kemudian kadar aspal optimal bisa ditentukan.

\section{Penentuan Nilai Kadar Aspal Optimum Campuran}

Dari penentuan kadar aspal optimum pada grafik hubungan VIM dengan kepadatan campuran diperoleh angka tertinggi. Pada campuran SMA halus kadar aspal optimum nilai dari VIM kecil karena Stone Matrix Asphalt memiliki lapisan yang tahan terhadap air yang dimana dapat melindungi lapisan dibawahnya.

\section{Pengujian Marshall Immersion}


Volume 3 Issue 4, Desember 2021

Maksud dari penelitian ini adalah melihat kemampuan campuran bahan tersebut terhadap waktu lamanya perendaman, suhu, dan air. Pengujian Marshall konvensional, yaitu campuran SMA dengan kadar aspal optimum. Hasil pengujian Marshall Immersion akan dibandingkan dengan hasil Marshall Konvensional untuk mendapatkan stabilitas Marshall sisa campuran tersebut [19] [20].

\section{ANALISA DAN PEMBAHASAN}

1. Karakteristik campuran

a. Perhitungan Bulk Spesific Gravity dan Effective Spesific Gravity

Tabel 2. Perhitungan Bulk Spesific Gravity dan Effective Spesific Gravity

\begin{tabular}{cccccc}
\hline & \multicolumn{5}{c}{ Kadar Aspal (\%) } \\
\cline { 2 - 6 } & $\mathbf{6 , 0 0 \%}$ & $\mathbf{6 , 2 5 \%}$ & $\mathbf{6 , 5 0 \%}$ & $\mathbf{6 , 7 5 \%}$ & $\mathbf{7 , 0 0 \%}$ \\
\hline $\begin{array}{c}\text { Bulk Spesific Gravity } \\
\text { Agrerat }\end{array}$ & 2.86 & 2.86 & 2.87 & 2.88 & 2.89 \\
\hline $\begin{array}{c}\text { Effective Spesific Gravity } \\
\text { Agrerat }\end{array}$ & 2.89 & 2.9 & 2.91 & 2.91 & 2.92 \\
\hline
\end{tabular}

\section{Hasil Pengujian Marshall Konvensional}

Tabel 3. Nilai Karakteristik Campuran

\begin{tabular}{ccccc}
\hline \multirow{2}{*}{$\begin{array}{c}\text { Kadar aspal } \\
(\boldsymbol{\%})\end{array}$} & VIM & Stabilitas & Flow & VMA \\
\cline { 2 - 5 } & 4.77 & 1694.13 & 2.94 & 18.39 \\
\hline $6,00 \%$ & 4.67 & 1751.42 & 2.55 & 18.9 \\
\hline $6,25 \%$ & 1803.61 & 2.34 & 19.29 \\
\hline $6,50 \%$ & 4.44 & 1816.22 & 2.6 & 19.79 \\
\hline $6,75 \%$ & 4.34 & 1587.73 & 3.39 & 20.19 \\
\hline $7,00 \%$ & 4.13 & $\mathbf{4} \%$ & $\mathbf{4 . 5}(\mathbf{m m})$ & Min. 17 (\%) \\
\hline Persyaratan & $\mathbf{4 - 5 \%}$ & Min. 600 (kg) & $\mathbf{2}$ & \\
\hline
\end{tabular}

\section{a. Analisis terhadap Stabilitas}

Dari tabel 3 diatas, nilai untuk stabilitas dibuatkan grafik hubungan dengan variasi kadar aspal seperti pada gambar 1 berikut.

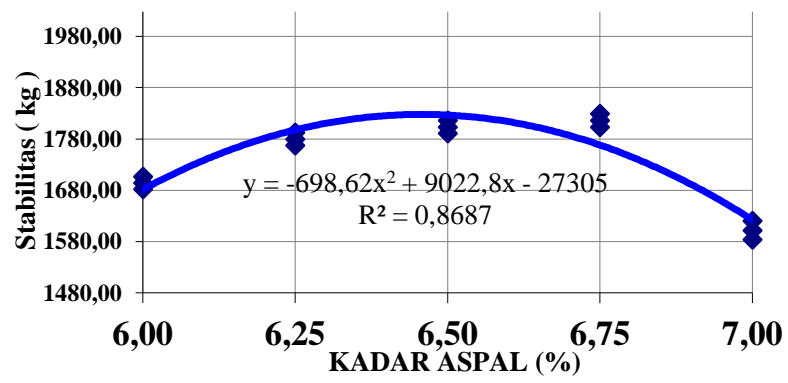

Gambar 1. Hubungan kadar aspal terhadap stabilitas 
Pada hasil stabilitas di atas dapat diketahui bahwa setiap kadar aspal untuk nilai stabilitas rata-ratanya mengalami kenaikan pada kadar aspal 6,00\%-6,75\% dan pada kadar kadar aspal 7,00\% mengalami penurunan. Sehingga dapat disimpulkan bahwa pemakaian kadar aspal yang sedikit pada campuran maka dapat mengakibatkan selimut aspal menjadi tipis pada permukaan agregat yang menyebabkan ikatan pada setiap agregat menjadi lemah, maka stabilitas pada campuran akan kecil, namun apabila aspal mengalami penambahan maka selimut aspal akan mengalami penebalan yang nantinya ikatan pada setiap agregat menjadi kuat sehingga stabilitas pada campuran menjadi besar. Tetapi apabila aspal makin bertambah banyak lagi dapat mengakibatkan makin tebalnya selimut aspal yang berakibat stabilitas pada campuran akan mengalami penurunan kembali.

\section{b. Analisa terhadap VIM (Void in Mix)}

Dari tabel 3 diatas, nilai untuk VIM dibuatkan grafik hubungan dengan variasi kadar aspal seperti pada gambar 1 berikut.

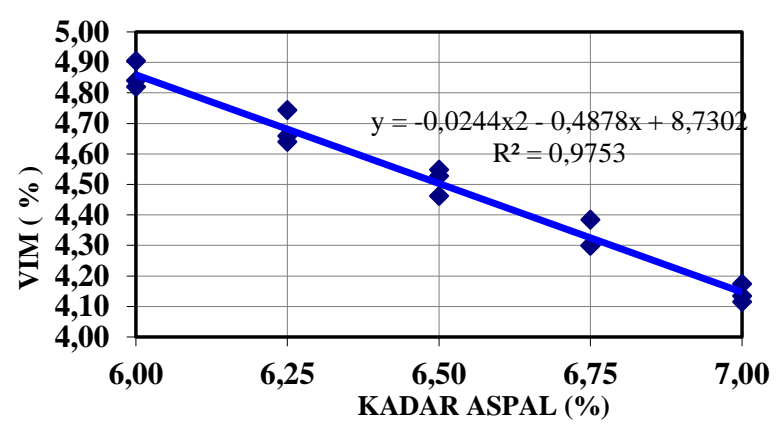

Gambar 2. Hubungan kadar aspal terhadap VIM

Pada hasil VIM di atas dapat diketahui bahwa pada kadar aspal yang digunakan mulai dari 6,00\%-7,00\% terjadi penurunan, di mana dapat disimpulkan bahwa penggunaan kadar aspal yang makin tinggi maka makin kecil pula nilai VIM yang didapatkan, sebaliknya jika penggunaan kadar aspal yang makin kecil maka makin besar nilai VIM yang didapatkan. Karena pada campuran beraspal kegunaan dari aspal yaitu sebagai pengisi dan pengikat.

\section{c. Analisa terhadap Flow}

Dari tabel 3 diatas, nilai untuk Flow dibuatkan grafik hubungan dengan variasi kadar aspal seperti pada gambar 1 berikut.

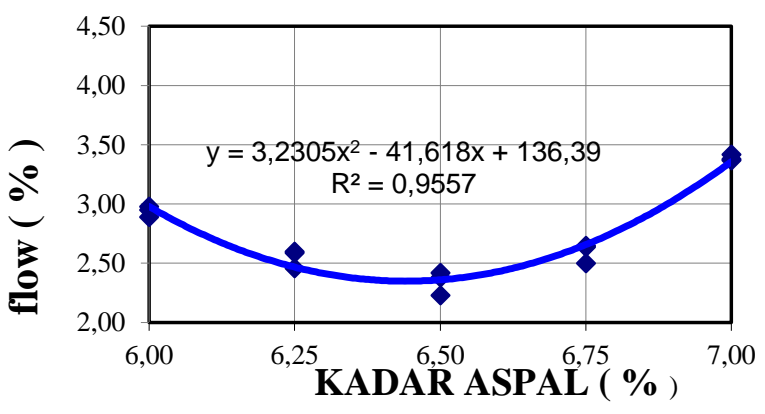

Gambar 3. Hubungan kadar aspal dan flow 
Dari hasil pengujian Flow di atas dapat dilihat bahwa dari kadar aspal 6,00\% - 6,50\% terjadi penurunan kemudian mengalami kenaikan pada kadar aspal 6,75\% - 7,00\%, apabila pada campuran beraspal penggunaan aspal yang sedikit maka akan mengakibatkan kelelehan besar yang di mana agregat yang saling mengikat akan berkuran. Namun apabila aspal yang digunakan bertambah banyak maka agregat yang saling terikat di dalam campuran akan lebih kuat yang di mana mengalami kelelehan menurun, Tetapi apabila aspal yang akan digunakan makin banyak lagi maka kekuatan campuran akan mengalami pengurangan yang diakibatkan makin menebalnya selimut aspal, tetapi kelelehan akan makin besar, di mana artinya flow (kelelehan campuran) akan berbanding terbalik dengan stabilitas (kekuatan campuran).

\section{d. Analisa terhadap VMA (Void in Mineral Aggregate)}

Dari tabel 3 diatas, nilai untuk VMA dibuatkan grafik hubungan dengan variasi kadar aspal seperti pada gambar 1 berikut.

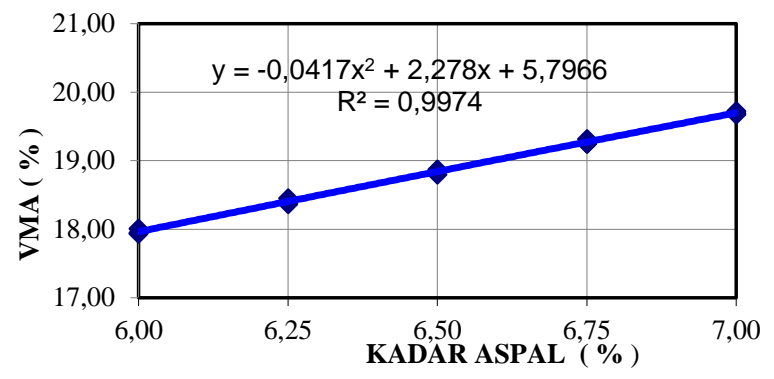

Gambar 4. Hubungan kadar aspal terhadap VMA

Dari hasil pengujian VMA di atas dikatakan memenuhi Spesifikasi Umum Bina Marga 2018 karena pada Tabel 25 untuk kadar aspal 6,00\% - 7,00\% didapatkan nilai VIM rata-rata yaitu 17,97\%-19,70\%. Kemudian dari grafik hubungan kadar aspal dengan VMA untuk kadar aspal 6,00\% - 7,00\% mengalami kenaikan hal ini dikarenakan aspal yang digunakan banyak. Penggunaan aspal yang makin banyak maka aspal akan makin besar mengisi rongga dalam agregat maka nilai VMA mengalami peningkatan. Pencampuran dan pemadatan dipengaruhi oleh aspal yang digunakan banyak, agregat akan diselimuti oleh aspal, dan rongga dalam agregat akan terisi oleh aspal.

\section{e. Penentuan Kadar Aspal Optimum}

Penentuan Kadar aspal optimum ditentukan dari hasil pengujian karakteristik melalui pengujian Marshall Konvensional. Dari hasil analisis campuran dapat diketahui bahwa untuk kadar aspal optimum pada campuran SMA halus dipilih yang memiliki nilai VIM paling kecil yaitu pada kadar aspal 7,00\% karena lapisan SMA merupakan lapisan aus atau lapis permukaan yang harus kedap air untuk menjaga lapisan dibawahnya.

\section{f. Stabilitas Marshall Sisa (SMS)}

Stabilitas Marshall sisa campuran Stone Matrix Asphalt halus diperoleh dari rasio / perbandingan / pembagian stabilitas campuran setelah direndam pada durasi waktu 24 jam dengan stabilitas campuran yang direndam selama 0,5 jam. Dari hasil pengujian Marshall Immersion didapatkan nilai stabilitas marshall sisa sebesar 92,02 dengan kadar aspal 7,00\%. Nilai stabilitas marshall sisa ini telah memenuhi Spesifikasi Umum Bina Marga 2018.

\section{KESIMPULAN}

Karakteristik agregat dari limbah beton memenuhi persyaratan untuk campuran perkerasan jalan.

Berdasarkan hasil rancangan komposisi pada campuran Stone Matrix Asphalt Halus didapatkan komposisi 
campuran untuk kadar aspal 7,00\% agregat kasar yaitu 69,00\%, agregat halus 15,67 \%, dan filler 8,33\%. Penggunaan campuran Stone Matrix Asphalt Halus melalui pengujian Karakteristik campuran Marshall Konvensional diperoleh nilai Stabilitas, Kelelehan (flow), Void In Mix (VIM), Void In Mix Aggeregate (VMA), memenuhi spesifikasi, dari hasil pengujian Marshall Immersion diperoleh indeks perendaman sebesar atau Indeks Kekuatan.

\section{DAFTAR PUSTAKA}

[1] F. Izzatur Rahman, A. Kristian Tambuna, 1. Djakfat and A. Zaceob, "KAJIAN PEMANFAATAN LIMBAH BETON SEBAGAI MATERIAL CEMENT TREATED BASE (CTB)," Fakultas Teknik Universitas Brawijaya, vol. 1, no. 3, pp. 1-12, 2015.

[2] Soelarso, Baehaki and N. Fatah Sidik, "PENGARUH PENGGUNAAN LIMBAH BETON SEBAGAIPENGGANTI AGREGAT KASAR PADA BETON NORMALTERHADAP KUAT TEKAN DAN MODULUS ELASTISITAS," vol. 5, no. 2, pp. 22-29, 2016.

[3] M. Purwoko Sidi, B. Wedyantadji and M. Erfan, "PENGARUH PENGUNAAN LIMBAH BETON SEBAGAI PENGGANTI AGREGAT DALAM CAMPURAN ASPAL BETON LAPIS AUS (AC-WC)," e-journal GELAGAR, vol. 2, no. 1, pp. 36-45, 2020.

[4] C. Kamba, "Agregat Dari Material Lokal," in Pemanfaatan Material Alternatif (Sebagai Bahan Penyusun Konstruksi), Makassar, Tohar Media, 2021, pp. 35 - 46.

[5] M. Apsari Panusingon, B. D.Handono and R. Pandaleke, "UJI EKSPERIMENTAL KUAT TEKAN BETON DAUR ULANG DENGAN BAHAN TAMBAH ABU TERBANG (FLY ASH) DAN SERBUK KACA SEBAGAI SUBSTITUSI PARSIAL SEMEN," Universitas Sam Ratulangi Fakultas Teknik Jurusan Sipil Manado, vol. 7, no. 1, pp. 52-66, Januari 2019.

[6] L. D. R. K. Salle, "Pemanfaatan Limbah," in Pemanfaatan Material Alternatif (Sebagai Bahan Penyusun Konstruksi), Makassar, Tohar Media, 2021, pp. 59 - 67.

[7] A. M Wagih, H. Z. El-Karmoty, M. Ebid and S. H. Okba, "Recycled construction and demolition concrete wasteas aggregate for structural concrete HBRC," HBRC Journal, vol. 9, no. 3, pp. 193-200, 2013.

[8] N. Imannurrohman, Sudarno and M. Amin, "Pemanfaatan Limbah Beton Sebagai Pengganti Agregat Kasar Pada Perkerasan Laston Asphalt Concrete - Wearing Coarse (AC-WC)," jurnal.untidar.ac.id/index.php/civilengineering/, vol. 04, no. 1, pp. 6-15, Maret 2020.

[9] A. Maulana, M. Amaliah and R. Utami, "Pemanfaatan Limbah Beton Sisa Pengujian Sebagai Substitusi Agregat Pada Campuran AC-WC," Jurusan Teknik Sipil Politeknik Negeri Bandung, vol. 22, no. 1, pp. 88-95, Maret 2020.

[10] R. Siang and A. Makmur, "PENGARUH PENGGUNAAN LIMBAH BETON TERHADAP PARAMETER MARSHALL CAMPURAN BERASPAL BERPORI," Universitas Kristen Krida Wacana, vol. 20, no. 2, pp. 97-104, 2020.

[11] U. Saepudin, "KAJIAN PENGGUNAAN LIMBAH BETON SEBAGAI PENGGANTI AGREGAT KASAR PADA CAMPURAN CEMENT TREATED BASE (CTB) UNTUK LAPIS PONDASI PERKERASAN LENTUR," Jurnal Media Teknologi, vol. 03, no. 01, pp. 13-22, Agustus 2016.

[12] B. Kurniawan Wilujeng and Y. Risdianto, "pemanfaatan limbah beton sebagai bahan campuran aspal porus," Universitas Negeri Surabaya, vol. 2, no. 1, pp. 1-6, 2019.

[13] A. Fatha Abdillah, N. Pradani and J. Fredi Batti, "PENGARUH PENGGUNAAN BAHAN TAMBAH VIATOP PADA CAMPURAN STONE MATRIX ASPHALT TERHADAP TITIK LEMBEK ASPAL DAN SIFAT DRAIN DOWN CAMPURAN," p. 10, 2018.

[14] N. Suaryana, "Kajian material Stone Matrix Asphalt Asbuton berdasarkan kritria deformasi permanen (a study of stone matrix asphalt asbuton material based on permanent deformation criterion)," Jurnal jalan, vol. 29, no. 2, pp. 66-81, 2012.

[15] T. Kurniawan and Z. Lubis, "alternatif penggunaan serat eceng gondok pada campuran stone matrix asphalt gradasi halus meningkatkan stabilitas campuran aspal panas," Universitas Islam Lamongan, vol. 3, no. 1, pp. 36-44, 2019.

[16] A. Dating Sandabunga, N. Ali and R. Rachman, "Karakteristik Campuran SMA Kasar Menggunakan Batu Sungai Sa'dan Kecamatan Sesean Toraja Utara," Universitas Kristen Indonesia Paulus Makassar, vol. 2, no. 4, 
pp. 282-287, Desember 2020.

[17] R. Rachman, "The Effect of Immersion and Humidification toward Performance of Hot Rolled Asphalt Mixture," International Journal of Applied Engineering Research, vol. 15, no. 5, pp. 503 - 509, 2020.

[18] R. Rachman, "Karakteristik Campuran HRS - BASE Menggunakan Bubuk Dolomit Sebagai Filler," in Prosiding Konferensi Nasional Teknik Sipil Ke-13 [KoNTekS-13], Banda Aceh, 2019.

[19] R. Adi Jansen, N. Ali and R. Rachman, "Pemanfaatan Batu Sungai Sa'dan Toraja Utara Sebagai Campuran Stone Matrix Asphalt Halus," Universitas Kristen Indonesia Paulus Makassar, vol. 2, no. 4, pp. 314-320, 2020.

[20] R. Rachman, "Pemanfaatan Batu Gunung Bottomale Toraja Utara sebagai Campuran Laston," Jurnal Teknik Sipil dan Teknologi Konstruksi, vol. 6, no. 1, pp. 20-30, 2020. 